\title{
Characteristics Of Pulmonary Arterial Hypertension in Children with Acyanotic Congenital Heart Disease
}

\author{
Shabrina Nur Imanina ${ }^{1}$, Taufiq Hidayat ${ }^{2 *}$, Yan Efrata Sembiring ${ }^{3}$, Mahrus A. \\ Rachman $^{2}$ \\ 2 taufiq-h@fk.unair.ac.id \\ ${ }^{1}$ Faculty of Medicine University Airlangga 60132, Surabaya, East java, Indonesia \\ ${ }^{2}$ Departement of Pediatric Dr. Soetomo General Hospital 60285, Surabaya, Indonesia \\ ${ }^{3}$ Departement of Thoracic, Cardiac and Vascular Surgery Dr. Soetomo General Hospital 60285, Surabaya Indonesia
}

\begin{abstract}
Background: Congenital heart disease is the leading cause of death in infants related to birth defects and can cause chronic defects [1]. The most common complication is pulmonary hypertension (PH). The worst manifestation of PAH is Eisenmenger syndrome. If it has manifested into Eisenmenger syndrome, the defect in CHD cannot be corrected $[2,3]$. Research on the characteristics of PAH in CHD needs to be known for better treatment.

Methods: This is a descriptive study in pediatric patients with acyanotic congenital heart disease. In this research we used medical records. Data analysis was carried out descriptively.

Results: The results of this study showed that the prevalence of PAH was $7.08 \%$, and most of the patients were toddlers (33 patients or $57.9 \%$ ) and female (38 patients of 66.7\%). The most common diagnosis of CHD lesions was ASD, found in 19 patients $(33.3 \%)$. Most patients came with severe PAH conditions. Pharmacological therapy in the form of sildenafil was mostly given. The most common symptoms were shortness of breath and murmurs on physical examination. There was no relationship between intervention variables, pharmacological therapy, and mortality and between diagnosis of CHD and severity of PAH.

Conclusion: Although the prevalence of PAH was not high in this study, the mortality rate was quite high. It is necessary to educate the parents of patients with congenital heart disease so that further complications can be prevented early on. It is also necessary to make services better to improve the nutritional status of patients. Pharmacological therapy and intervention measures need to be reviewed and improved to reduce mortality in patients.
\end{abstract}

Keywords : pulmonary hypertension;pulmonary arterial hypertension, ; congenital heart defect ; acyanotic ; pediatric.

\section{Main text}

\section{Introduction}

Congenital heart disease is the leading cause of death in infants related to birth defects, and it may result in chronic defects. It has caused Indonesia to incur high treatment costs. The incidence of this disease is estimated at up to 43,200 cases out of 4.8 million live births (9:1000 live births) annually. The most common type of CHD is left-to-right shunt acyanotic CHD. If not immediately corrected, it will cause complications, which are often found in the lungs. Complications of left-to-right shunt acyanotic CHD include pulmonary hypertension (HP) [4,5]

In Indonesia, it is estimated that there are 25,000 patients who have pulmonary hypertension [6]. The prevalence of HP caused by CHD is 5\% to $10 \%$ in adult patients. In children, HP occurs in 2 to 16 cases per one million children [7]. The research conducted by RSUP Dr. Sardjito revealed that as many as $77.1 \%$ of 1,102 patients had pulmonary hypertension [8]. Pulmonary hypertension is classified into five groups based on its pathophysiology, etiology, clinical features, hemodynamic characteristics, and therapeutic management. Pulmonary hypertension in CHD is classified as pulmonary arterial hypertension. 
Pulmonary arterial hypertension in pediatric patients is rare. In pediatric cases, it is commonly found in patients who are with CHD, especially acyanotic CHD with septal defects [9,10]. Pulmonary arterial hypertension, if not treated immediately, can cause pressure to increase, leading to a right-to-left shunt reversion in a condition known as Eisenmenger syndrome. Eisenmenger syndrome is the most severe form of pulmonary arterial hypertension. In Indonesia, especially in the province of Yogyakarta, in 2018, it was found that $68.7 \%$ of 800 patients had PAH and Eisenmenger syndrome at a young age. If Eisenmenger syndrome manifestation has started, the defect in CHD cannot be corrected and it will even require an intervention in the form of heart-lung organ transplantation $[2,3]$.

It is necessary to conduct research to determine the characteristics of pediatric patients with pulmonary arterial hypertension, especially in the city of Surabaya. Through this study, the characteristics of pulmonary arterial hypertension in pediatric patients with left-to-right shunt acyanotic CHD in need of a surgical intervention were investigated, which included basic characteristics, degree of PAH, clinical symptoms, physical examination, and prevalence of PAH. Patient mortality rate and the relationship between several variables were also examined.

\section{Materials and Methods}

Research with retrospective descriptive method was conducted at RSUD Dr. Soetomo Surabaya using the medical records of patients from the pediatrics department registered from January to December 2019. The population of this study was all acyanotic congenital heart disease patients aged 0-18 years with pulmonary arterial hypertension at RSUD Dr. Soetomo Surabaya in the time frame from January to December 2019. The inclusion criteria set for this research were patients aged 0 to 18 years and having left-to-right shunt acyanotic CHD. Meanwhile, patients with cyanotic congenital heart disease obstructive lesions and incomplete medical record data were excluded.

Each patient's information regarding basic characteristics, nutritional status, diagnosis of acyanotic congenital heart disease, pulmonary arterial hypertension degree, pharmacological therapy, intervention measures, and accompanying diseases as well as information on patient mortality after receiving treatment was collected from medical records.

\section{Results}

There were a total of 804 children with acyanotic congenital heart disease. The incidence of acyanotic CHD without PAH well exceeded that of acyanotic CHD with PAH (747 patients vs 57 patients, or $92.91 \%$ vs $7.08 \%$ ).

Table 1. Basic Characteristics of Patients

\begin{tabular}{lll}
\hline Characteristics & $\mathbf{N}(\mathbf{5 7})$ & $\mathbf{\%}$ \\
\hline Age & & \\
\hline Toddler $<5$ years & 33 & 57.9 \\
\hline Child & 19 & 33.3 \\
\hline Teen & 5 & 8.8 \\
\hline Sex & & \\
\hline Male & 19 & 33.3 \\
\hline Female & 38 & 66.7 \\
\hline
\end{tabular}


Diagnostic of Acyanotic CHD

\begin{tabular}{|c|c|c|}
\hline ASD & 19 & 33.3 \\
\hline VSD & 17 & 29.8 \\
\hline PDA & 4 & 7.0 \\
\hline AVSD & 1 & 1.8 \\
\hline ASD \& VSD & 7 & 12.3 \\
\hline VSD \& PDA & 4 & 7.0 \\
\hline ASD \& PDA & 2 & 3.5 \\
\hline ASD, VSD, \& PDA & 3 & 5.3 \\
\hline \multicolumn{3}{|c|}{ Degree of Pulmonary Hypertension } \\
\hline Mild & 8 & 14.0 \\
\hline Moderate & 11 & 19.3 \\
\hline Severe & 38 & 66.7 \\
\hline \multicolumn{3}{|l|}{ Nutritional Status } \\
\hline \multicolumn{3}{|l|}{ Age $<5$ y.o } \\
\hline Severely wasted & 11 & 19.3 \\
\hline Wasted & 8 & 14 \\
\hline Normal & 10 & 10 \\
\hline Overweight & 2 & 3.5 \\
\hline Obese & 2 & 3.5 \\
\hline \multicolumn{3}{|l|}{ Age $>5$ y.o. } \\
\hline Severely thin & 6 & 10.5 \\
\hline Thin & 6 & 10.5 \\
\hline Normal & 11 & 19.3 \\
\hline Obese & 1 & 1.8 \\
\hline
\end{tabular}

According to Table 1, under-five acyanotic congenital heart disease patients with pulmonary artery hypertension were most commonly found at RSUD Dr. Seotomo Surabaya in the period January-December 2019, and female patients outnumbered their male counterparts (38 patients or $66.7 \%$ ). The most common type of left-to-right shunt acyanotic congenital heart disease found in the patients was atrial septal defect (19 patients or $33.3 \%$ ). From observation it was also found that some patients were diagnosed with more than one type of congenital heart disease: 2 patients $(3.5 \%)$ were diagnosed with ASD and PDA, 4 patients $(7 \%)$ with VSD and PDA, 7 patients (12.3\%) with ASD and VSD, and 3 patients (5.3\%) with all the three of ASD, VSD, and PDA.

Most of the patients (38 patients or $66.7 \%$ ) were found to have a severe degree of disease. We tried to identify the relationship between degree of PAH and diagnosis of congenital heart disease, but we found no relationship between the two variables.

Tabel 2. Clinical symptoms

\begin{tabular}{lll} 
Symptoms & N & $\%$ \\
\hline
\end{tabular}




\begin{tabular}{lll}
\hline Breathlessness & 34 & 59.6 \\
\hline Cough & 22 & 38.6 \\
\hline Fever & 20 & 35.1 \\
\hline Shortness of breath during activity & 6 & 10.5 \\
\hline Cyanosis during activity & 6 & 10.5 \\
\hline Loss of weight & 6 & 10.5 \\
\hline Cyanosis & 5 & 8.8 \\
\hline Cold & 4 & 7 \\
\hline Vomit & 4 & 7 \\
\hline Pale & 2 & 3.5 \\
\hline Seizure & 2 & 3.5 \\
\hline Blue from birth & 1 & 1.8 \\
\hline Angina & 1 & 1.8 \\
\hline No symptoms & 8 & 14 \\
\hline
\end{tabular}

From Tabel 2 we can see that the five clinical symptoms often found in patients were breathlessness, cough, fever, shortness of breath when doing strenuous activities, and cyanosis when doing activities. However, there were 8 patients $(14 \%)$ who came to the hospital without any clinical symptoms.

Tabel 3. Physical Examination

\begin{tabular}{cc}
\hline Physical & $\mathbf{N}(\mathbf{\%})$ \\
\hline Murmur & $29(50.9)$ \\
\hline Thorax retraction & $22(38.6)$ \\
\hline Dyspnea & $13(22.8)$ \\
\hline Anemia & $11(19.3)$ \\
\hline Ronchi & $8(14)$ \\
\hline Gallop & $6(10.5)$ \\
\hline Delirium consciousness & $5(8.8)$ \\
\hline Cyanosis & $4(7)$ \\
\hline Icterus & $3(5.3)$ \\
\hline Clubbing finger & $2(3.5)$ \\
\hline Stridor & $1(1.8)$ \\
\hline Nostril breath & $1(1.8)$ \\
\hline Acral Cyanosis & $1(1.8)$ \\
\hline Wheezing & $1(1.8)$ \\
\hline Hepatomegaly & $1(1.8)$ \\
\hline Normal & $15(26.3)$
\end{tabular}


The three most common results of physical examination were murmurs, thoracic retractions, and dyspnea. Murmurs were present in 29 patients $(50.9 \%)$, followed by thoracic retractions in 22 patients $(38.6 \%)$ and dyspnea in 13 patients $(22.8 \%)$. Nonetheless, in 15 patients $(26.3 \%)$ the results were within normal limits.

Tabel 4. Co-morbidities

\begin{tabular}{lcc}
\hline Co-morbidities & N & $\%$ \\
\hline Pneumonia & 16 & 28.0 \\
\hline Rheumatic Heart Disease & 9 & 15.8 \\
\hline Acute Kidney Failure & 2 & 3.5 \\
\hline Asthma & 1 & 1.8 \\
\hline Hypothiroid & 1 & 1.8 \\
\hline Atrial Fibrilation & 1 & 1.8 \\
\hline Down Syndrome & 1 & 1.8 \\
\hline Hydrocephalus & 1 & 1.8 \\
\hline Acute tonsilitis & 1 & 1.8 \\
\hline Umbilical Hernia & 1 & 1.8 \\
\hline Atresia \& Stenosis Rectum & 1 & 1.8 \\
\hline Cellulitis\& Lymphangitis & 1 & 1.8 \\
\hline Hepatitis & 1 & 1.8 \\
\hline Without co-morbidities & 27 & 47.4 \\
\hline
\end{tabular}

The most common co-morbidity was pneumonia, which occurred in 16 patients (28\%), followed by rheumatic heart disease in 9 patients $(15.8 \%)$. Patients without co-morbidities were also found quite a lot, numbering $27(47.4 \%)$.

Tabel 5. PAH Spesific Treatment

\begin{tabular}{llll}
\hline & Drug & N & \% \\
\cline { 2 - 4 } & Sildenafil & 34 & 59.6 \\
\cline { 2 - 4 } PAH Spesific Therapy & Sildenafil +Dorner & 3 & 5.3 \\
\cline { 2 - 4 } & Dorner & 1 & 1.8 \\
\cline { 2 - 3 } & No Medication & 19 & 33.3 \\
\hline
\end{tabular}


Patients coming to the hospital were treated in either of two ways, namely pharmacological drugs and intervention.

Based on Table 5, it was found that of a total of 57 patients most were given sildenafil pharmacological therapy (34 patients or 59.6\%). Three patients received a specific combination therapy for PAH of sildenafil and Dorner $(35.1 \%)$ and one other $(1.8 \%)$ received a specific therapy for HAP of Dorner. Another 19 patients were not treated for pulmonary arterial hypertension.

Tabel 6. Heart Failure Symptoms Treatment

\begin{tabular}{llll}
\hline & \multicolumn{1}{l}{ Drug } & N & \% \\
\cline { 2 - 4 } & Furosemid & 20 & 35.1 \\
\cline { 2 - 4 } $\begin{array}{l}\text { Heart Failure Symptoms } \\
\text { Therapy }\end{array}$ & Spironolakton & 16 & 28.1 \\
\cline { 2 - 4 } & Digoxin & 3 & 5.3 \\
\cline { 2 - 4 } & Dobutamin & 3 & 5.3 \\
\cline { 2 - 3 } & Lisionapril & 19 & 33.3 \\
\cline { 2 - 3 } & Captopril & 4 & 1.8 \\
\cline { 2 - 3 } & Bisoprolol & 1 & 7 \\
\hline
\end{tabular}

According to Table 6, some patients received a drug therapy for symptoms of heart failure. The therapy given is not only of one type of drug. The most frequently administered drugs were furosemide (in 20 patients or $35.1 \%$ ), lisionapril (in 19 patients or $33.3 \%$ ), and spironolactone (in 16 patients or $28.1 \%$ ).

Tabel 7 Intervention Procedure

\begin{tabular}{lll}
\hline Intervention Procedure & N & $\%$ \\
\hline Yes & 23 & 40.4 \\
\hline No & 34 & 59.6 \\
\hline Total & 57 & 100 \\
\hline Intervention Procedure & $\mathrm{N}$ & $\%$ \\
\hline Transcatheter & 8 & 34.8 \\
\hline Surgical Operation & 11 & 47.8 \\
\hline Transcatheter \& Surgical Operation & 4 & 17.4 \\
\hline Total & 23 & 100 \\
\hline
\end{tabular}

According to Table 7, most acyanotic congenital heart disease pediatric patients with PAH did not receive any intervention (34 patients or $59.6 \%$ ), while 23 patients $(40.4 \%$ ) did.

The intervention given could be in the form of transcatheter (in 8 patients or $34.8 \%$ ) or surgery according to the diagnosis of congenital heart disease (in 11 patients or $47.8 \%$ ). Another 4 patients $(17.4 \%)$ received both interventions. 
A total of 45 patients came home alive, 27 of whom (47.3\%) lived without correction in their heart and 18 $(31.6 \%)$ did with recovery after being given intervention measures for their congenital heart disease. Meanwhile, 12 other patients $(21.1 \%)$ died.

We tried to find a correlation between intervention procedure in patients and mortality, but we found no relationship between the two. It was also found that there was no correlation between the administration of pharmacological therapy and mortality.

\section{Discussion}

The incidence of pulmonary arterial hypertension in acyanotic CHD was $7.08 \%$. A similar number was also found in a study in the Netherlands, in which the incidence of PAH in adult CHD patients was found to be 4.2\% [11]. Meanwhile, the research at RSUD Dr. Moewardi Surakarta showed that the incidence of PAH in children with acyanotic CHD was $56.7 \%$ [12].

\subsection{Basic Characteristics}

Most patients were at the age of under 5 years (33 patients or 57.9\%). A similar case was also found by Vongpatanasin et al. [13], where $80 \%$ of PDA and VSD patients developed Eisenmenger syndrome, which is the most severe manifestation of PAH, in infancy. In Yogyakarta province it was found that $68.7 \%$ of 800 patients had PAH and Eisenmenger syndrome at a young age [3]. This finding could be because the diagnosis of CHD is usually made in childhood at 1 week to 1 month early in life [14].

In this study, the data obtained showed that of 57 left-to-right acyanotic CHD pediatric patients with PAH, 38 were female $(66.7 \%)$ and 19 were male $(33.3 \%)$. Other research also showed that pulmonary arterial hypertension is always found in more women than men. PAH in CHD was found in $60 \%$ of female patients [10]. In the UK and USA, female PAH patients made up $70 \%$ and $80 \%$ of all patients, respectively. There is also a general consensus that women are at a greater risk for PAH based on research that showed that the ratio of women to men in PAH group was 3:1 $[15,16]$. Several theories that are thought to be associated with the high incidence of PAH in left-to-right shunt acyanotic CHD in women are BMP, spontaneous closure of the defect, and biologic artery diameter [17].

ASD diagnoses were more common in child patients with pulmonary arterial hypertension than VSD. This is in contrast to that found by Pascall in the UK. He found that pulmonary artery hypertension was the most common in VSD congenital heart disease $[10,14]$. In this study several patients were found to be with more than one diagnosis. For instance, seven patients were diagnosed with ASD and VSD at once. The same thing was also found in China, in which 10 out of 56 patients had more than one diagnosis of CHD. Six of those 10 were discovered to have both ASD and VSD [18]. More ASD cases were found in this study probably because ASD tends to be asymptomatic. Therefore, ASD was undetected at an early stage and only found when complications occurred. These complications included pulmonary arterial hypertension [19].

PAH was mostly found in patients at a severe degree (38 patients or $66.7 \%$ ). This could be because 16 of the 57 patients also had more than one type of septal defect, which of course would result in greater right-toleft heart blood flow. The size of the defect affected the degree of PAH, in which case large defects in ASD would result in a severe degree of PAH [10].

Good nutritional status (normal) was mostly found in patients aged 5-18 years, while poor nutritional status (severely wasted) was mostly found in patients at the age of $0-5$ years. The same thing was also found in 
Enugu and a previous study conducted at RSUD Dr. Soetomo Surabaya in 2012: pulmonary arterial hypertension increased the risk for wasting in CHD and caused lower heights and weights in pediatric patients than when PAH is non-existent [20,21]. Infants have a higher risk of developing malnutrition [22]. Patients aged over 5 years may have received early intervention so that malnutrition can be prevented [21].

\subsection{Clinical Symptoms}

The most common clinical symptom found in this study was shortness of breath, which could be due to a co-morbid disease that was mostly found in the patients in this study, namely pneumonia. This co-morbid disease was found in 16 patients. Shortness of breath was also found in Abassia Chest Hospital in Egypt [23]. Research in Turkey found the same symptoms with 52\% of WHO FC III because of shortness of breath [8,24].

\subsection{Physical Examination}

In this study at RSUD Dr. Soetomo Surabaya, the 3 most common results found were murmurs, retractions on the thorax, and no physical abnormalities. Murmurs are sounds caused by turbulence in the blood flow in the heart. In pulmonary arterial hypertension there is regurgitation of the tricuspid valve due to right ventricular dilatation. This dilation is caused by the right ventricle not having enough pressure to push blood into the lungs which have too high a pressure [25,26]. This correlates with the findings of this study, that most of the patients had severe pulmonary arterial hypertension.

The retractions of the thorax were found to be due to difficulty in breathing, which was a clinical symptom in 38 patients in this study; this symptom urged the use of the chest muscles to help breathe [27].

\subsection{Co-morbidities}

In this study, the most common co-morbidity found in patients was pneumonia (in 16 patients). In addition, the number of patients without co-morbidities was also found to be quite large (27 patients). The same thing was also found in RSUP Dr. Djamil in Padang and RSUP Dr. Hasan Sadikin in Bandung: pneumonia was the most common co-morbidity found in congenital heart disease. Lung infections in patients can be due to malnutrition [5,28], which is also quite common in this study. Malnutrition in patients can increase the risk of infection and death [22].

\subsection{PAH Spesific Treatment}

Patients in this study received specific PAH therapy and treatment for symptoms of heart failure. The specific therapy often given is sildenafil. The same thing was also found in Poland, in which sildenafil was the most widely used [29]. The use of sildenafil in CHD children with PAH can increase oxyhemoglobin saturation and exercise capacity without significant side effects. In addition to providing minimal side effects, sildenafil is also sold for an affordable price. In a study of 25 children with PAH associated with chronic lung disease (including bronchopulmonary dysplasia, CHD, PPHN, and pulmonary hypoplasia), 88\% showed improvement in echocardiographic measurements of pulmonary hypertension (HP) after a mean duration of sildenafil treatment of 40 days [30,31]. 


\subsection{Intervention Procedure}

Most of the patients did not receive any intervention. Performing surgery on patients with pulmonary arterial hypertension has risks. In this study where many patients came with severe PAH, there was a risk of a pulmonary hypertension crisis after surgery, which could accelerate the disease progression and the onset of right ventricular failure [32,33]. This reason might underlie why in this study left-to-right shunt acyanotic CHD patients with PAH more often did not receive any intervention.

Forty-five patients were discharged alive after receiving treatment from RSUD Dr. Soetomo Surabaya, 18 of whom recovered after receiving intervention. Meanwhile, 12 other patients died. Congenital heart disease with pulmonary arterial hypertension has a worse prognosis. The mortality rate in PAH-CHD is said to be quite high and has been reported more frequently than other etiologies of PAH [33]. Based on observations of medical records, patient deaths can be caused by either of the following two things: heart failure and septic shock.

\section{Conclusion}

In conclusion, this study provides information on the characteristics of acyanotic congenital heart disease pediatric patients with PAH at RSUD Dr. Soetomo Surabaya Indonesia from January to December 2019, especially those aged 0 to 18 years. Toddler, female patients with a severe degree of PAH and ASD defect were the most common patients. Most under-five patients had poor nutritional status, while many of those aged 5-18 years had good nutritional status. The most common symptoms were shortness of breath and murmurs on physical examination. Sildenafil was widely used, but intervention procedure was mostly not given. Although the prevalence of PAH-CHD in this study was not high, the mortality rate was quite high. It is considered necessary to conduct further research on pulmonary arterial hypertension in congenital heart disease involving a longer period of time using primary data and cross-sectional analytical methods. It is also necessary to educate the parents of patients with congenital heart disease so that further complications can be prevented early on as well as to make services better to improve the nutritional status of patients. Pharmacological therapy and intervention measures need also to be reviewed and improved to reduce mortality in patients.

\section{Acknowledgements}

The author would like to thank the Faculty of Medicine Universitas Airlangga, Dr.Soetomo general hospital, doctors who have guided the author and other related parties who have facilitated and enabled this research to be completed.

\section{References}

[1] Reller MD, Strickland MJ, Riehle-Colarusso T, Mahle WT, Correa A. Prevalence of Congenital Heart Defects in Metropolitan Atlanta, 1998-2005. J Pediatr [Internet]. 2008;23(1):1-7. Available from: https://www.ncbi.nlm.nih.gov/pmc/articles/PMC3624763/pdf/nihms412728.pdf

[2] Nashat H, Montanaro C, Li W, Kempny A, Wort SJ, Dimopoulos K, et al. Atrial septal defects and pulmonary arterial hypertension. J Thorac Dis. 2018;10(4):S2953-65.

[3] Dinarti LK, Hartopo AB, Murni IK, Dewanto VC, Pritazahra A, Hadwiono MR, et al. Rationale and Study Design: The Screening of Congenital Heart Disease by Cardiac Auscultation and 12-Leads Electrocardiograph Examination in First-grade Elementary School Children in Province of Yogyakarta, Indonesia. Res Sq. 2019;1-15. 
[4] Finariawan F, Mahmud S.A. S. The Characteristics and Distribution of Congenital Heart Disease in Outpatient Clinic and Inpatient Ward of RSUD Dr. Soedono Madiun East Java in Year 2015. ACI (Acta Cardiol Indones. 2018;4(1):9.

[5] Hermawan BJ, Hariyanto D, Aprilia D. Profil Penyakit Penyakit Jantung Bawaan Di Instalasi Rawat Inap Anak Rsup Dr. M. Djamil Padang Periode Januari 2013 - Desember 2015. J Kesehat Andalas. 2018;7(1):142.

[6] Wahyudi F. Mengenal Hipertensi Pulmonal [Internet]. Pusat Jantung Nasional. 2021 [cited 2021 Aug 30]. Available from: https://www.pjnhk.go.id/artikel/mengenal-hipertensi-pulmonal

[7] Hansmann G. Pulmonary Hypertension in Infants, Children, and Young Adults. J Am Coll Cardiol. 2017;69(20):2551-69.

[8] Dinarti LK, Hartopo AB, Kusuma AD, Satwiko MG, Hadwiono MR, Pradana AD, et al. The COngenital HeARt Disease in adult and Pulmonary Hypertension (COHARD-PH) registry: A descriptive study from single-center hospital registry of adult congenital heart disease and pulmonary hypertension in Indonesia. BMC Cardiovasc Disord. 2020;20(1):1-11.

[9] Van Loon RLE, Roofthooft MTR, Hillege HL, Ten Harkel ADJ, Van Osch-Gevers M, Delhaas T, et al. Pediatric pulmonary hypertension in the Netherlands: Epidemiology and characterization during the period 1991 to 2005. Circulation. 2011;124(16):1755-64.

[10] Pascall E, Tulloh RM. Pulmonary hypertension in congenital heart disease. Future Cardiol. 2018;14(4):343-53.

[11] Duffels MGJ, Engelfriet PM, Berger RMF, van Loon RLE, Hoendermis E, Vriend JWJ, et al. Pulmonary arterial hypertension in congenital heart disease: An epidemiologic perspective from a Dutch registry. Int J Cardiol. 2007;120(2):198-204.

[12] Herlambang G, Widjaja SL, Hafidh Y, Salimo H. Hubungan Rasio Neutrofil Limfosit dengan Hipertensi Arteri Pulmonal pada Anak dengan Penyakit Jantung Bawaan Asianotik. 2019;21(2):96-101.

[13] Vongpatanasin W, Brickner EM, Hillis D, Lange RA. The Eisenmenger syndrome in adults. J Am Coll Cardiol. 1998;34(1):223-32.

[14] Mohammad N, Shaikh S, Memon S, Das H. Spectrum of heart disease in children under 5 years of age at Liaquat University Hospital, Hyderabad, Pakistan. Indian Heart J [Internet]. 2014;66(1):145-9. Available from: http://dx.doi.org/10.1016/j.ihj.2013.12.041

[15] Mair KM, Johansen AKZ, Wright AF, Wallace E, Maclean MR. Pulmonary arterial hypertension: Basis of sex differences in incidence and treatment response. Br J Pharmacol. 2014;171(3):567-79.

[16] Ge X, Zhu T, Zhang X, Liu Y, Wang Y, Zhang W. Gender differences in pulmonary arterial hypertension patients with BMPR2 mutation: A meta-analysis. Respir Res. 2020;21(1):1-10.

[17] Verheugt CL, Uiterwaal CSPM, Van Der Velde ET, Meijboom FJ, Pieper PG, Vliegen HW, et al. Gender and outcome in adult congenital heart disease. Circulation. 2008;118(1):26-32.

[18] Xi SB, Wang SS, Qian MY, Xie YM, Li JJ, Zhang ZW, et al. Predictors of operability in children with severe pulmonary hypertension associated with congenital heart disease. Chin Med J (Engl). 2019;132(7):811-8.

[19] Post MC. Association between pulmonary hypertension and an atrial septal defect. Netherlands Hear J. 2013;21(7-8):331-2.

[20] Irawan R, Elizabeth R, Hidayat T, Utamayasa IKA, Rahman MA. Anthropometric Profile of Children With Cyanotic and Non-Cyanotic Congenital Hearth Disease. 2020;15(1):1-6.

[21] Arodiwe I, Chinawa J, Ukoha M, Ujunwa F, Adiele K, Onukwuli V, et al. Nutritional status of children with congenital heart disease (CHD) attending university of Nigeria teaching hospital ituku - ozalla, Enugu. Pakistan J Med Sci. 2015;31(5):11405.

[22] Herridge J, Tedesco-Bruce A, Gray S, Floh AA. Feeding the child with congenital heart disease: a narrative review. Pediatr Med. 2021;4:7-7.

[23] Farrag M, Elfattah NA, Younis MA. Demographic and clinical characteristics of pulmonary hypertension cases and the awareness of the disease among chest physicians in Abassia Chest Hospital. Egypt J Chest Dis Tuberc [Internet]. 2016;65(1):295-301. Available from: http://dx.doi.org/10.1016/j.ejcdt.2015.10.011

[24] Kaymaz C, Mutlu B, Serdar Küçükoğlu M, Kaya B, Akdeniz B, Avcı BK, et al. Preliminary results from a nationwide adult cardiology perspective for pulmonary hypertension: Registry on clinical outcome and survival in pulmonary hypertension groups (SIMURG). Anatol J Cardiol. 2017;18(4):242-50.

[25] Poland AT, France PD, Uk SH, Uk TH, Germany HO, Uk AP, et al. Guidelines on diagnosis and treatment of pulmonary arterial hypertension: The Task Force on Diagnosis and Treatment of Pulmonary Arterial Hypertension of the European Society of Cardiology. Eur Heart J. 2004;25(24):2243-78.

[26] Lilly LS. Pathophysiology of Heart Disease A Colaborative Project of Medical Students and Faculty. 5th ed. Baltimore: Lippincott Williams \& Wilkins; 2011.

[27] Barton ED, English J. Respiratory distress. Rosen Barkin's 5-Minute Emerg Med Consult Fifth Ed. 2014;(c):1-2.

[28] Gabriela K, Kuswiyanto RB, Dwiyatnaningrum F. Clinical Characteristic and Outcome of Acute Lower Respiratory Tract Infection in Children with Congenital Heart Disease. Althea Med J. 2015;2(3):403-8.

[29] Kwiatkowska J, Zuk M, Migdal A, Kusa J, Skiba E, Zygielo K, et al. Children and Adolescents with Pulmonary Arterial Hypertension: Baseline and Follow-Up Data from the Polish Registry of Pulmonary Hypertension (BNP-PL). J Clin Med. 2020;9(6):1717. 
[30] Prawira Y, Yanuarso PB. Sildenafil Sebagai Pilihan Terapi Hipertensi Pulmonal Pascabedah Jantung Koreksi Penyakit Jantung Bawaan pada Anak. Sari Pediatr. 2016;11(6):456.

[31] Avitabile CM, Vorhies EE, Ivy DD. Drug Treatment of Pulmonary Hypertension in Children. Pediatr Drugs [Internet]. 2020;22(2):123-47. Available from: https://doi.org/10.1007/s40272-019-00374-2

[32] Widlitz A, Barst RJ. Pulmonary arterial hypertension in children. Eur Respir J. 2003;21(1):155-76.

[33] D’Alto M, Mahadevan VS. Pulmonary arterial hypertension associated with congenital heart disease. Eur Respir Rev. 2012;21(126):328-37. 